Preference is given to letters commenting on contributions published recently in the JRSM. They should not exceed 300 words and should be typed double spaced

\section{Empowerment for patients with medically unexplained symptoms}

In a JRSM paper last year, Salmon and Hall ${ }^{1}$ challenged the doctrine of patient empowerment, arguing that the consequent transfer of responsibility can be harmful. In their brief mention of medically unexplained symptoms they did not refer to evidence that 'empowering explanations' can have positive impact. ${ }^{2,3}$

There is a distinction between feeling responsible for the management of symptoms and feeling responsible for the cause of a disease. In patients with medically unexplained symptoms, empowering explanations are those that take the onus of responsibility for the cause of symptoms away from the patient. ${ }^{4}$

Responsibility implies culpability. We are teaching our patients to blame themselves for their illnesses. You have had a heart attack because you chose to smoke, ate the wrong foods, took too little exercise. In the past, people viewed illness as poor luck but we are now learning a new aetiology - that of individual behavioural determinism. The message is clear. Your heart attack is your own fault.

This is a deeply unpalatable message for the unwell and generates an emotionally charged conflict, especially apparent in syndromes of medically unexplained symptoms. The clinical challenge is to lessen patients' feeling of responsibility for the cause of the illness whilst at the same time helping them to establish a feeling of control and power over the symptoms. Salmon and Hall highlight the danger of empowerment when doctors and patients focus only on symptom control and ignore issues of aetiology. Empowering explanations must address both cause and control of illness if they are to alleviate rather than exacerbate the patient's distress.

\section{Joe Butchart}

Directorate of Medicine and Elderly Care,

Southampton General Hospital,

Tremona Road, Southampton SO16 6YD, UK

E-mail: jwbutchart@doctors.org.uk

\section{REFERENCES}

1 Salmon P, Hall GM. Patient empowerment or the emperor's new clothes. J R Soc Med 2004;97:53-6

2 Burton C. Beyond somatisation: a review of the understanding and treatment of medically unexplained physical symptoms (MUPS). Br J Gen Pract 2003;53:233-41

3 Page LA, Wessely S. Medically unexplained symptoms: exacerbating factors in the doctor-patient encounter. J R Soc Med 2003;96:223-7
4 Salmon P, Peters S, Stanley I. Patients' perceptions of medical explanations for somatisation disorders: qualitative analysis. BMJ 1999;318:372-6

\section{Good teachers: substainable models}

Dr Azer (February 2005, JRSM ${ }^{1}$ ) lists the qualities of a good teacher but is less persuasive on how these can be developed and sustained. In the UK, for example, teaching is just one of seven duties of a doctor. Other duties are to provide good clinical care, maintain good working relationships with patients and colleagues and maintain high standards of probity. ${ }^{2}$ What if one duty conflicts with another-for example, what if you are called to a patient or to a team meeting in the middle of a tutorial? There are no right or wrong answers but there is much to be said for involving patients in the education of medical students. This can reduce the workload for ourselves. In one study, students who had been taught pelvic examination by specially trained laywomen showed better skills than students taught in the conventional way. ${ }^{3}$ Similarly, patients trained in arthritis education can teach musculoskeletal examination skills. ${ }^{4}$ Perhaps more importantly, such patient-educators can encourage medical students to realize the impact of chronic arthritis on daily life. ${ }^{4}$ Colleagues from other disciplines can also be recruited, to increase the resources and support available, though time is needed to surmount the traditional barriers and provide an integrated programme. $^{5}$

\section{Kieran Walsh}

8 Elmhurst Villas, Cheltenham Road, London SE15 3AE, UK

E-mail:kmwalsh@bmjgroup.com

\section{REFERENCES}

1 Azer SA. The qualities of a good teacher: how can they be acquired and sustained? J R Soc Med 2005;98:67-9

2 General Medical Council. A Licence to Practise and Revalidation. London: GMC, 2003

3 Pickard S, Baraitser P, Rymer J, Piper J. Can gynaecology teaching associates provide high quality effective training for medical students in the United Kingdom? Comparative study. BMJ 2003; 327:1389-92

4 Gruppen LD, Branch VK, Laing TJ. The use of trained patient educators with rheumatoid arthritis to teach medical students. Arthritis Care Res 1996;9:302-8

5 Pipas CF, Peltier DA, Fall LH, et al. Collaborating to integrate curriculum in primary care medical education: successes and challenges from three US medical schools. Fam Med 2004;36(suppl.): S126-32

\section{MRSA}

The latest development in the saga of methicillin-resistant Staphylococcus aureus, reviewed by Dr Newsom in his useful editorial (November 2004, JRSM ${ }^{1}$ ), is the emergence of 
community-acquired MRSA (CA-MRSA) in various parts of the world. ${ }^{2-4}$ One wonders about the future, especially when the manifestations have included severe necrotizing pneumonia in previously healthy individuals. In a study from Taiwan, carriage of MRSA was identified in a substantial proportion of schoolchildren without any apparent risk factors. ${ }^{5}$ Another report suggests, alarmingly, that CA-MRSA may have its own independent origins, distinct from hospital-originated strains. ${ }^{6}$ Despite vigorous attempts at containment, it seems that MRSA is undergoing this microbiological evolution in several parts of the world. Novel approaches will be needed, to counter these epidemiological trends.

\section{P Dileep Kumar}

3409 Ancient Dr, Port Huron, MI 48060, USA

\section{REFERENCES}

1 Newsom SWB. MRSA - past, present, future. J R Soc Med 2004;97: 509-10

2 Witte W, Braulke C, Cuny C, et al. Emergence of methicillin-resistant Staphylococcus aureus with Panton-Valentine leukocidin genes in central Europe. Eur J Clin Microbiol Infect Dis 2004 Dec 15 [Epub ahead of print]

3 Murray RJ, Lim TT, Pearson JC, Grubb WB, Lum GD. Communityonset methicillin-resistant Staphylococcus aureus bacteremia in Northern Australia. Int $J$ Infect Dis 2004;8:275-83

4 CDC. Methicillin-resistant Staphylococcus aureus infections among competitive sports participants, Colorado, Indiana, Pennsylvania, and Los Angeles County, 2000-2003. MMWR 2003;52:793-5

5 Huang YC, Su LH, Lin TY. Nasal carriage of methicillin-resistant Staphylococcus aureus in contacts of an adolescent with communityacquired disseminated disease. Pediatr Infect Dis J 2004;23:919-22

6 Carleton HA, Diep BA, Charlebois ED, Sensabaugh GF, PerdreauRemington F. Community-adapted methicillin-resistant Staphylococcus aureus (MRSA): population dynamics of an expanding community reservoir of MRSA. J Infect Dis 2004;190:1730-8

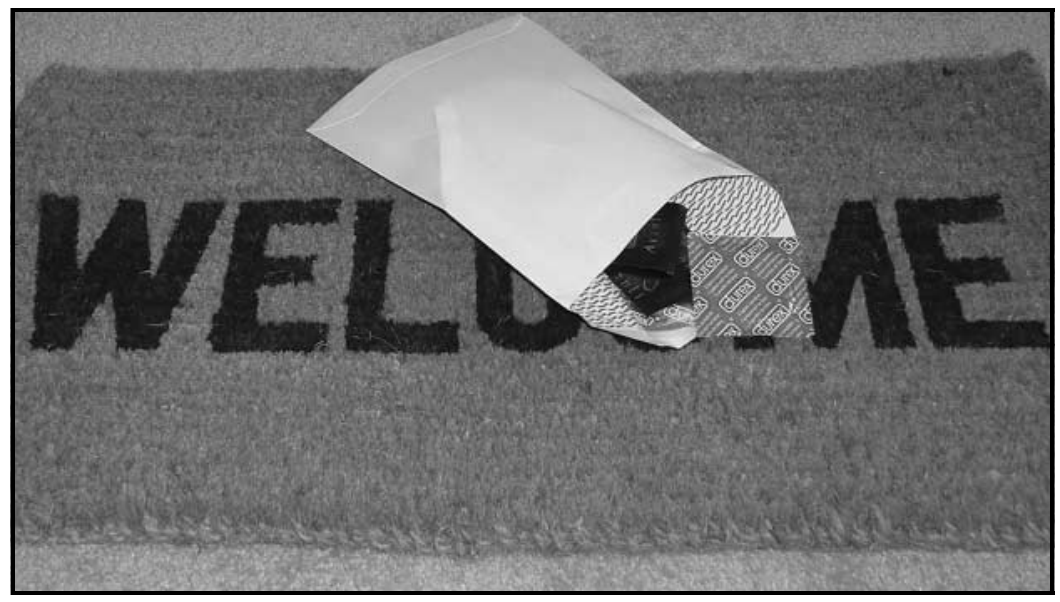

\section{Condoms on a doormat}

For the Brooke Photography Competition, the RSM's Section of Epidemiology and Public Health set the subject 'The Broad Street Pump in 2004'. The prizewinning entry, above, was by Miranda Mindlin and Marianne Walker. They say that, like Snow's historic intervention in identifying and stopping a cholera-contaminated water source, today's efforts to prevent sexually transmitted infections are based on excellent epidemiological information together with an understanding of transmission mechanisms: 'We have shown condoms on a doormat to illustrate the way an effective public health intervention has to "penetrate" from the public space of policy to the private space of the home and individual action. The legend "Welcome" on the doormat alludes to a positive reception for health promotion campaigns while referring obliquely to sexual permissiveness. 